\title{
MAPEAMENTO DAS TRILHAS DO PARQUE ESTADUAL DA SERRA DA TIRIRICA (RJ): PLANEJAMENTO PARA A GESTÃO DO USO PÚBLICO
}

\author{
Bruno Fernandes G. Cova ${ }^{1}$ \\ Douglas de Souza Pimentel ${ }^{2}$
}

\section{Resumo}

O Parque Estadual da Serra da Tiririca representa um caso emblemático de área protegida cercada por uma malha urbana. O uso público dessas trilhas pode causar grandes impactos que devem ser monitorados e mitigados. Entre muitos problemas relacionados à utilização de trilhas, há a compactação e erosão do solo, aparecimento de voçorocas e ravinas, movimentos de massa graves, aparecimento de espécies exóticas, queimadas, vandalismo, entre outros. O uso público dessas trilhas é agravado pelo fato desse parque estadual não ter ainda um plano de manejo. Além disso, é esperado um aumento da visitação, relacionado aos grandes eventos esportivos no Rio de Janeiro. Esse trabalho objetiva mapear e gerar uma descrição de trilhas do Parque com o intuito de monitorar, evitar ou mitigar impactos relacionados aos diferentes usos. Os inícios da trilha do Bananal e do Morro das Andorinhas estão bastante impactados. A segunda precisa ser estruturada para o trabalho de Educação Ambiental com crianças. Então mais do que nunca é preciso lutar e preservar para os futuros visitantes essas áreas que guardam além da riqueza natural da Mata Atlântica, um passado de ocupação histórico-cultural que marca o processo de formação sócio-espacial do estado do Rio de Janeiro.

Palavras chave: Mapeamento; trilhas; uso público.

\begin{abstract}
The Serra da Tiririca State Park represents an emblematic case of a protected area surrounded by a growing urban environment. The public use of these trails can cause major impacts that must be monitored and mitigated. Among many problems related to the use of these trails, could be mentioned soil compaction, soil erosion, appearance of gullies and ravines, serious mass movements, appearance of exotic species, fire, and vandalism, among others. Public use of these trails is compounded by the fact that this state park does not obtain a management plan yet, despite it being in progress. So, the intention of this work is to map and generate a description of the trails in order to monitor, prevent or mitigate impacts related to different uses. Besides that, at the moment, a demographic boom of visits is expected, since we're on the verge of realizing major sporting events. The Bananal and Morro das Andorinhas' Trails are very impacted. The second one should be structured to environment education activities, realized with children. So more than ever we need to fight and preserve these areas for future visitors, besides the natural wealth of the Atlantic Forest, there is a historical-cultural process that marks the socio-spatial formation of the state of Rio de Janeiro.
\end{abstract}

Keywords: Mapping; trails; public use.

\footnotetext{
${ }^{1}$ Bruno Fernandes G. Cova: Universidade Federal Fluminense - E-mail: nobru.fernandes@hotmail.com

${ }^{2}$ Douglas de Souza Pimentel: Universidade Federal Fluminense - E-mail: douglasgeia@gmail.com
} 


\section{Introdução}

Muitas trilhas utilizadas hoje são caminhos formados naturalmente pelo pisoteio de animais para diferentes atividades, como a realização de movimentos migratórios, busca por alimentos e parceiros reprodutivos (FIGUEIREDO et al., 2010). Sendo assim, ao se deparar com uma floresta, os seres humanos normalmente seguiam esses caminhos naturais para facilitar os deslocamentos, consolidando a trilha. Sabe-se hoje, que muitas estradas e rodovias derivam de trilhas antigas. No caso dos parques, muitas trilhas utilizadas para o uso público eram caminhos historicamente percorridos pelas comunidades próximas e tiveram o seu objetivo alterado para facilitar a visitação dessas áreas protegidas e, portanto, devem ser geridas sob essa consideração, pois as unidades de conservação (UCs) possuem, além da beleza cênica, características naturais relevantes que justificam sua proteção e regime especial de administração (BRASIL, 2002).

O Parque Estadual da Serra da Tiririca (PESET) foi criado pela Lei Estadual 1.901 de 29 de novembro de $1991^{3}$. Atualmente, pode-se considerar a área do Parque é formada por um conjunto de fragmentos florestais, sem corredores ecológicos para conectá-los, o que dificulta os esforços de conservação da UC (Figura 01). No âmbito das relações socioambientais, as bordas desses fragmentos ainda são ameaçadas pela especulação imobiliária em Niterói. Esse fato é tão presente que recentemente houve uma consulta pública onde se tratou da questão de anexação da Reserva Ecológica Darcy Ribeiro (1.165 hectares), Morro da Peça (45 hectares), e Ilhas Pai, Mãe e Menina (50 hectares) ao PESET. Sendo assim, o Parque aumentou de 2.260 hectares para 3.520 hectares (INEA, 2012) ${ }^{4}$. Há, portanto, uma série de conflitos relacionados ao seu território, o que aumenta a necessidade de ganho de significado da conservação para a sociedade. Assim, o processo de institucionalização da área (PIMENTEL; MAGRO, 2012), também passa pela estruturação das trilhas do Parque para diferentes formas de uso público.

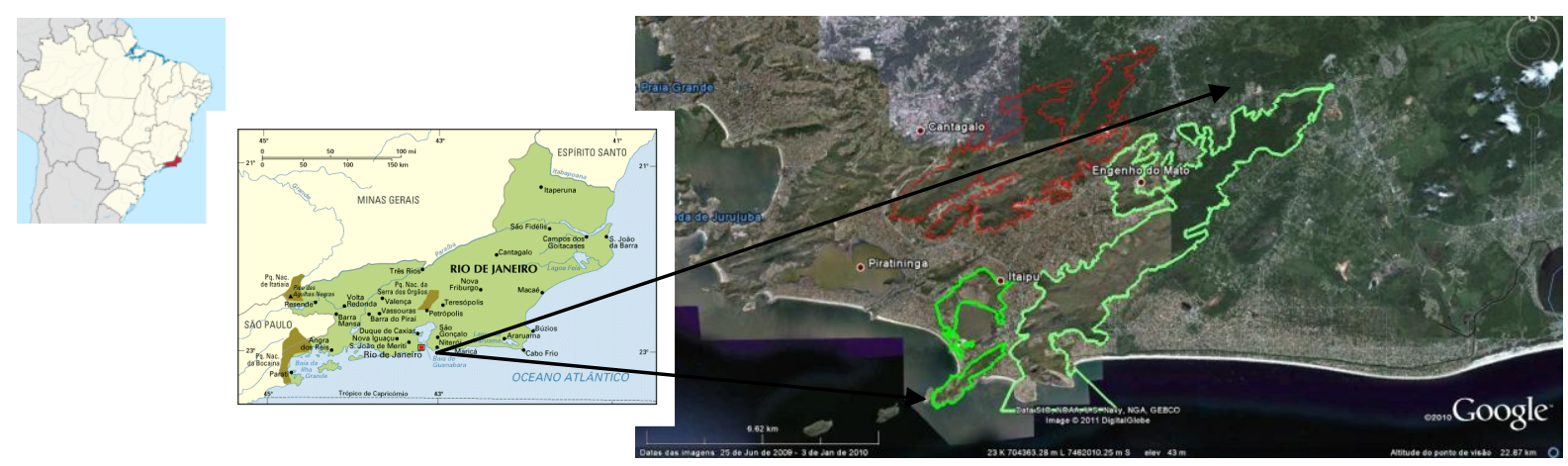

Figura 01. Localização do PESET no estado do Rio de Janeiro (Fonte: Google Earth).

\footnotetext{
${ }^{3}$ LEI Estadual 1.901: Disponível em: http://www.inea.rj.gov.br/legislacao/docs/1901.doc. Acesso em 21 de Maio de 2013.

${ }^{4}$ INEA, 2012: Disponível em:< http://urutau.proderj.rj.gov.br/inea_imagens/downloads/Proposta_de_ampliacao_do_PESET.pdf $>$ Acesso em 21 de Maio de 2013.
} 
O PESET contém resquícios de Mata Atlântica, inúmeras espécies endêmicas, costões rochosos, restingas, o que o torna um patrimônio natural brasileiro e uma área de crescente interesse para a pesquisa científica, ecoturismo, recreação e educação ambiental. Legalmente, os diferentes usos possíveis desse recorte espacial são restringidos em comparação às formas de uso nas unidades de uso sustentável, onde é considerada a presença histórica das comunidades tradicionais que reproduzem a sua cultura em um longo tempo de ocupação. Portanto, fala-se de duas formas completamente diferentes de uso para as trilhas situadas nessas áreas com diferentes categorias de manejo. No caso das UCs de proteção integral, a visitação tem que ser controlada e monitorada. Porém, o PESET, por estar localizado em meio a uma área urbana densamente povoada, apresenta uma intensa visitação. Logo há necessidade de avaliação de impactos da visitação nas suas trilhas. Esse processo de monitoramento parte da descrição física das trilhas existentes, bem como de seu mapeamento.

Determinar pontos de interpretação ambiental de trilhas em parques, também auxilia na gestão do uso público, uma vez que a apreciação da área pelos visitantes e seu comportamento são extremamente influenciados por essa escolha (MAGRO; FREIXÊDAS, 1998). A qualidade da visitação está, geralmente, relacionada à segurança de uma trilha, bem como ao ganho de informações ambientais que ela proporciona ao visitante. No caso do PESET, raríssimas vezes as trilhas são guiadas por um profissional qualificado para tal tarefa. Além disso, informações que deveriam ser básicas, como mapas do caminho, sinalização em placas, tempo de duração média da trilha, pontos críticos, curiosidades biológicas, históricas, entre outras, são inexistentes ou precárias. O Parque recebe uma quantidade grande de visitantes. Como exemplo, a trilha Itacoatiara - Alto Mourão que se encontrava altamente degradada e erodida foi interditada, não por que o PESET possui um planejamento de abertura e manutenção de trilhas e sim como uma reação emergencial frente aos riscos que o caminho oferecia aos visitantes.

A proximidade com os grandes eventos e chegada de turistas estrangeiros promoveu certa mobilização e recentemente algumas medidas estão sendo tomadas. Podemos citar a iniciativa do órgão gestor do parque (INEA) em promover a estruturação dessas trilhas, para o possível aumento do seu uso, com o projeto Trilhas da Copa ${ }^{5}$. No caso do PESET, seis trilhas receberão tratamento especial, sendo elas a trilha dos Colibris, do Alto Mourão, do Costão de Itacoatiara, do Bananal, das Andorinhas e do Morro dos Crentes. O objetivo básico dos gestores é promover a sinalização e instituição de equipamentos e intervenções, como placas, lixeiras, bancos, pontes e escadas. O presente trabalho almeja apresentar o mapeamento e descrição física de algumas trilhas do PESET, passo inicial para melhor planejamento e gestão do seu uso público.

\footnotetext{
${ }^{5}$ Revitalização das trilhas: Trilhas no Parque da Serra da Tiririca serão recuperadas. Disponível em: < http://oglobo.globo.com/niteroi/trilhas-no-parque-da-serra-da-tiririca-serao-recuperadas-8169775>. Acesso em: 21 maio 2013.
} 


\section{Material e métodos}

O presente trabalho resulta de ações relacionadas a diferentes projetos realizados pela equipe do Grupo de Estudos Interdisciplinares do Ambiente (GEIA) da Faculdade de Formação de Professores da UERJ.

Os procedimentos para definição dos indicadores de impactos do uso público foram adaptados a partir da leitura de Bayfield e McGowan (1986), Bayfield (1987), Magro (1999), em como Passold, Magro e Couto (2004). Assim as atividades do GEIA vem definindo indicadores aplicáveis às trilhas de Mata Atlântica, factíveis de serem empregados pela gestão de parques. Assim os indicadores selecionados foram primariamente utilizados para a realização de uma descrição física da trilha do Morro das Andorinhas. Foi realizada uma amostragem sistemática com pontos localizados em intervalos de $50 \mathrm{~m}$. Os parâmetros seguintes foram avaliados: 1) Largura total; 2) Largura da trilha; 3) Solo exposto; 3) Declividade paralela e 4) Declividade perpendicular; 5) trilhas sociais; 6) Rugosidade; 7) Área da seção transversal; 8) Compactação do solo; 9) Umidade; 10) Fatores depreciativos qualitativos e quantitativos estatisticamente significativos e 11) Fatores favoráveis.

Para o mapeamento das trilhas, os dados cartográficos foram coletados com o uso do aparelho de GPS Garmin ETrex 30. Com os dados coletados pelo aparelho, e com o uso de recursos e programas importantes como o MapSource e o TrackMaker, que ajudam na visualização dos pontos e trajetos gerados, definiram-se os trajetos percorridos, bem como a localização dos pontos amostrais das coletas em campo e pontos de interpretação ambiental. Informações físicas da trilha como perfis topográficos e mapas temáticos, formarão um banco de dados referentes ao Sistema de Informação Geográfica (GIS) da área em questão, para possível uso da gestão do Parque.

\section{Resultados e Discussão}

\section{a) A trilha do Morro das Andorinhas}

Para a descrição física da trilha do Morro das Andorinhas, foram demarcados 15 pontos amostrais no GPS (Figura 02). Essa trilha apresenta $833 \mathrm{~m}$ de extensão, podendo-se percorrê-la num tempo médio de 20 minutos. O caminho começa numa altura de $38 \mathrm{~m}$ próximo da Igreja de Itapu e culmina no mirante da montanha com $147 \mathrm{~m}$, conforme os dados da Tabela I. Esse último ponto é utilizado para atividades de interpretação ambiental em trabalhos do Museu de Arqueologia de Itaipu com escolas da região. Como essas atividades são realizadas com crianças, precisam ser consideradas as condições de segurança e as propriedades cênicas da paisagem, um dos principais atrativos que determina sua escolha como ponto final de parada. 


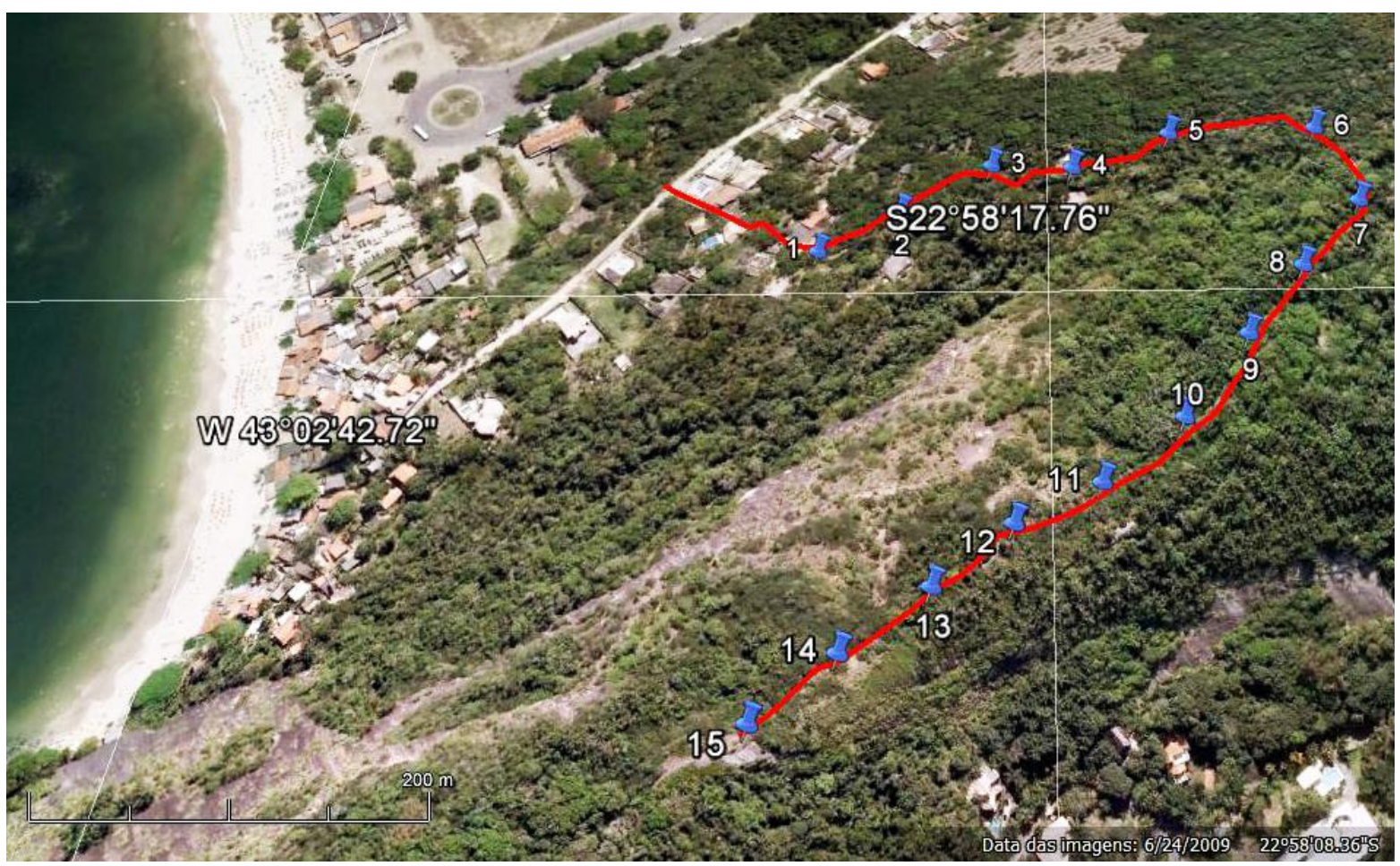

Figura 02- Trajeto da Trilha do Morro das Andorinhas até o ponto de interpretação ambiental no mirante voltado para a praia de Itacoatiara (Fonte: Google Earth).

Tabela I. Características gerais da Trilha do Morro das Andorinhas

\begin{tabular}{|c|c|}
\hline Característica & Informação \\
\hline Extensão & 833 metros \\
\hline Duração média do percurso & 20 minutos \\
\hline Velocidade média do percurso & $2,5 \mathrm{~km} / \mathrm{h}$ \\
\hline Início da trilha (altitude) & 38 metros (Igreja de Itaipu) \\
\hline Final da trilha (altitude) & 147 metros (Mirante) \\
\hline
\end{tabular}

A Figura 03 indica a maior intensidade de erosão encontrada nos pontos 1, 3, 4, 5 e 6. O início da trilha é ocupado por residências da comunidade tradicional de pescadores, que se mobilizaram intensamente direito de permanência no Parque. Portanto, além do uso turístico e recreacional, há o deslocamento regular dos moradores do local. 


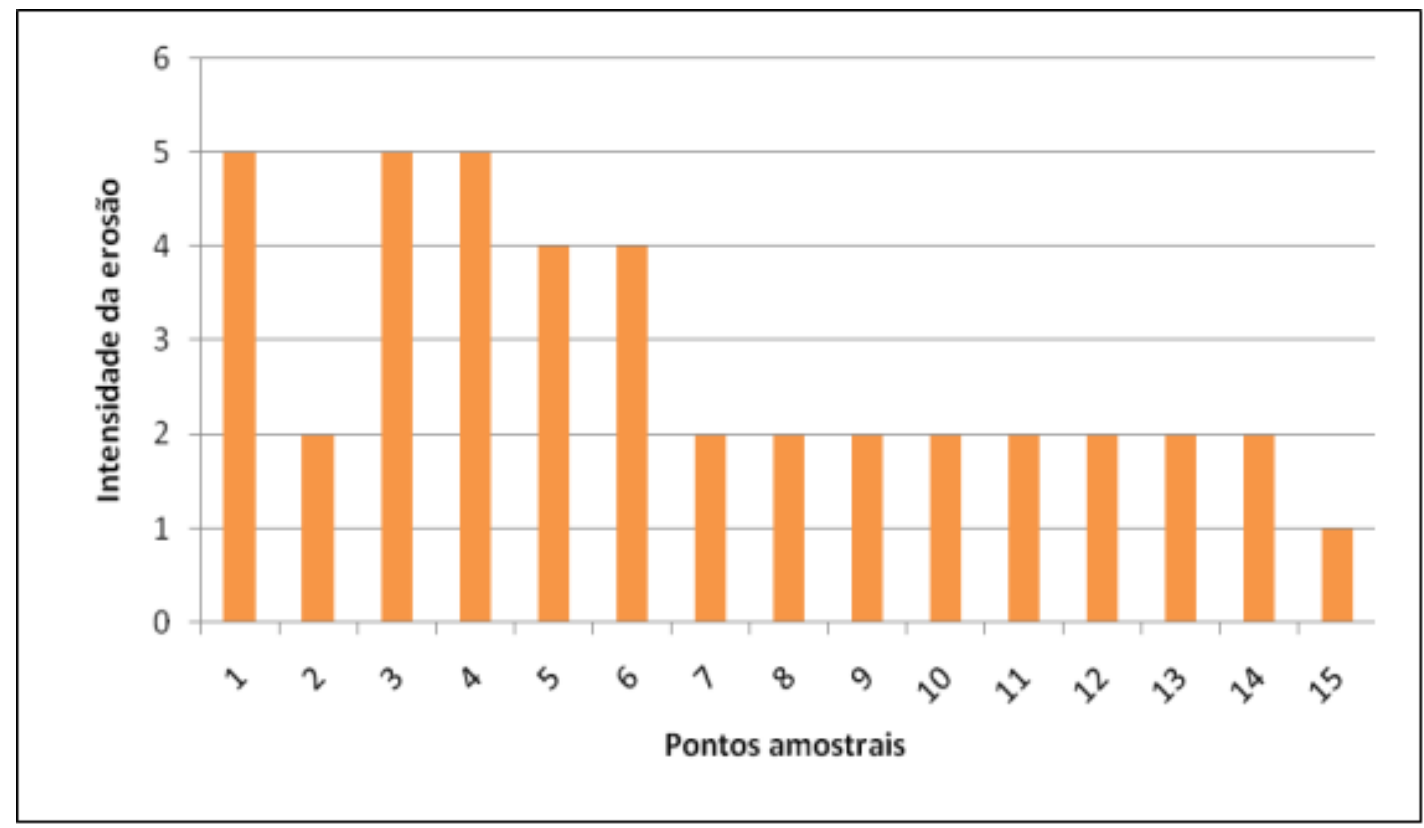

Figura 03. Intensidade de erosão nos 15 pontos amostrais da trilha do Morro das Andorinhas

Os 71 pontos registrados no GPS permitiram a geração do perfil topográfico desta trilha, a fim de orientar os visitantes para os pontos mais íngremes, ou críticos, como pode ser observado na Figura 04. Essa observação é importante, uma vez que existem atividades com crianças nesta trilha e deve-se pensar no seu deslocamento e segurança. Como mencionado anteriormente, esse foi o parâmetro balizador da escolha do mirante para interpretação ambiental, como pode ser observado na Figura 05.

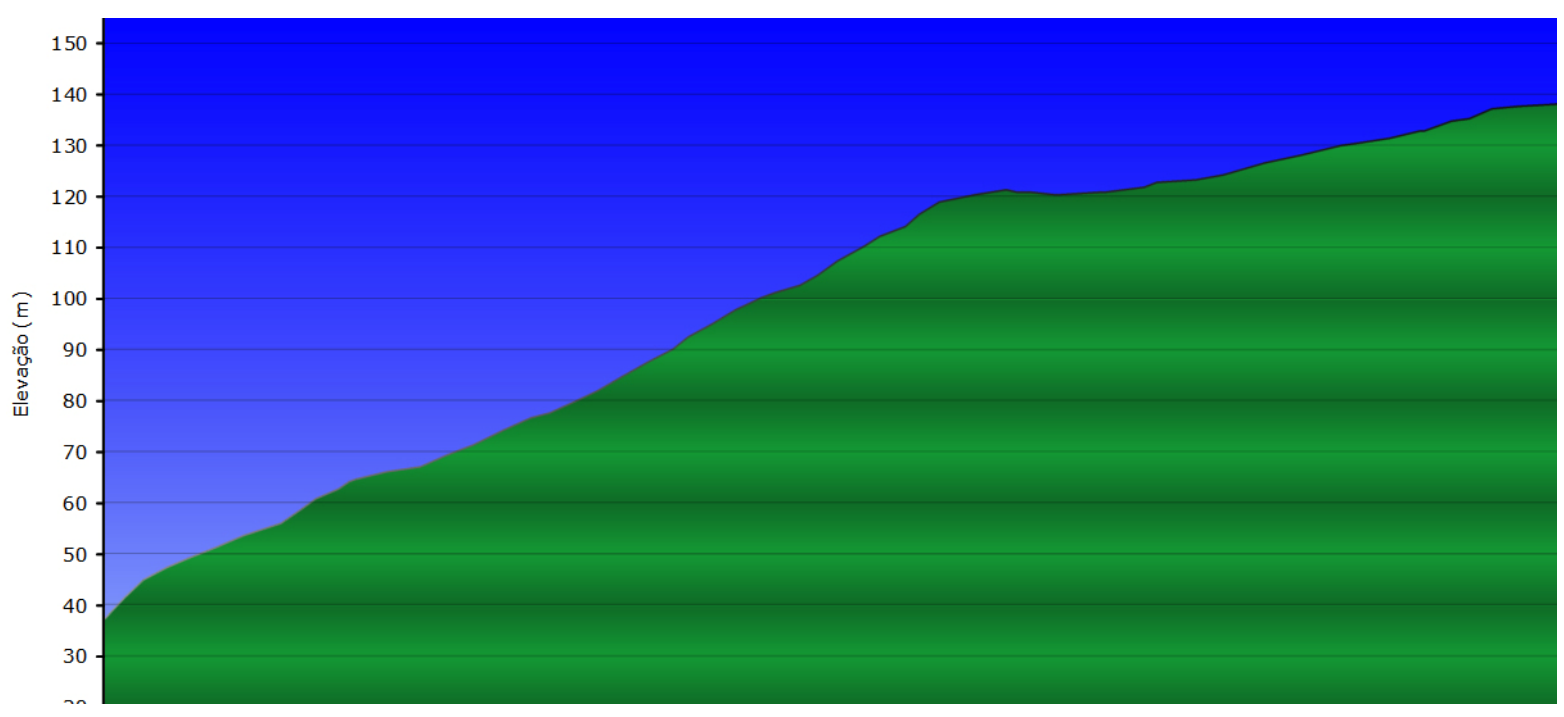

Figura 04. Perfil topográfico da Trilha do Morro das Andorinhas 


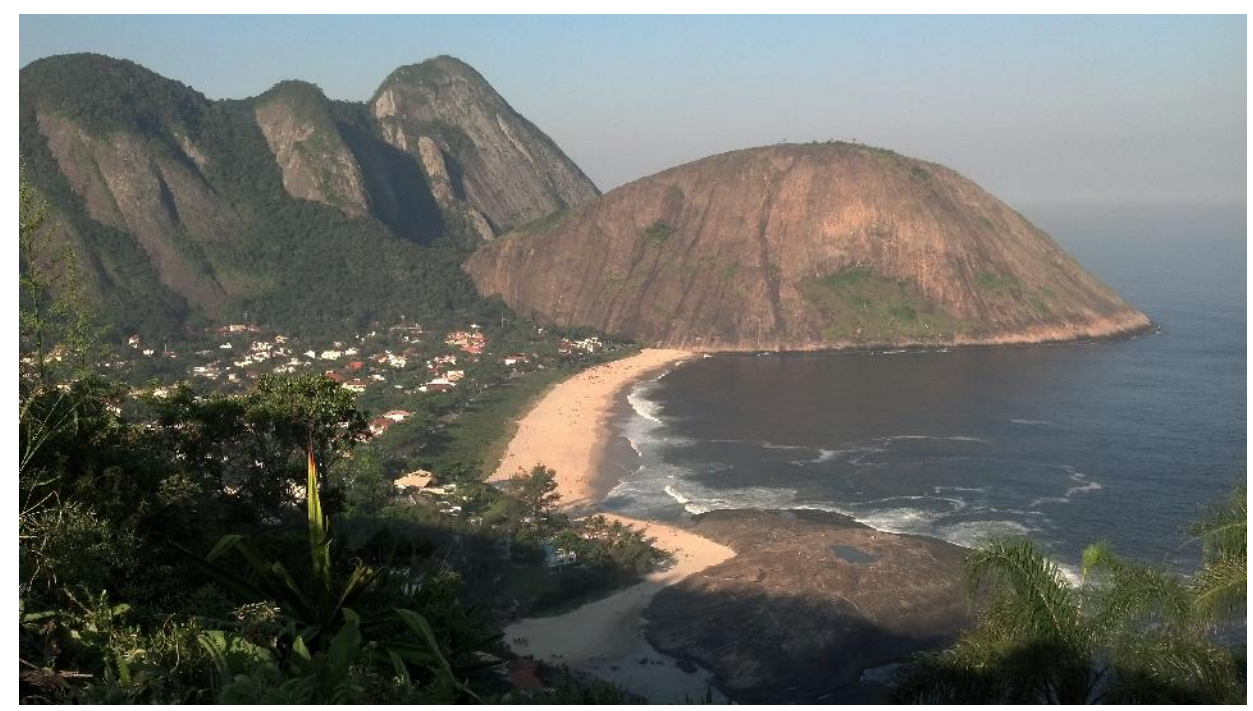

Figura 05. Mirante do Morro das Andorinhas. Dia 30.04.2013. Fonte: Bruno Fernandes

\section{b) A Trilha do Alto Mourão}

Esta trilha já foi mapeada, entretanto ainda falta a prospecção de indicadores de erosão. Com o uso de GPS, pode-se determinar o real trajeto percorrido neste caminho e com margem de erro máximo de 3 metros, pela combinação e captação dos satélites americanos e russos (sistema GLONASS), como mostra a Figura 06.

Os dados sobre a trilha estão sistematizados na Tabela II e no perfil topográfico da Figura 07. Foram demarcados 182 pontos e seu percurso total é de $1800 \mathrm{~m}$, com tempo médio de 40 minutos de subida. A trilha começa na altitude de $157 \mathrm{~m}$ no mirante do Itaipuaçu (limítrofe entre os municípios de Niterói e Maricá) e termina no topo da montanha com 412m.

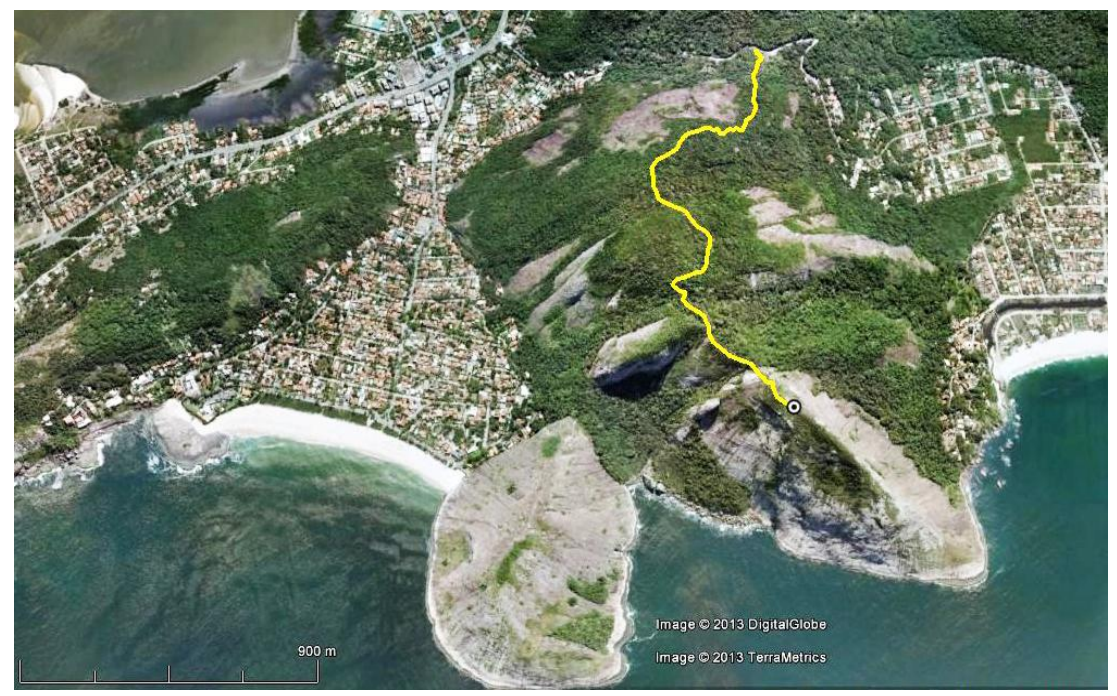

Figura 06. Trajeto da Trilha do Alto Mourão (Fonte: Google Erath). 
Tabela II. Dados sobre a Trilha do Alto Mourão/PESET

\begin{tabular}{|c|c|}
\hline Característica & Informação \\
\hline Extensão & 1800 metros \\
\hline Duração média do percurso & 40 minutos \\
\hline Velocidade média do percurso & $2,7 \mathrm{~km} / \mathrm{h}$ \\
\hline Início da trilha (altitude) & 157 metros (Mirante de Itaipuaçu) \\
\hline Final da trilha (altitude) & 412 metros (Mirante do Alto Mourão) \\
\hline
\end{tabular}

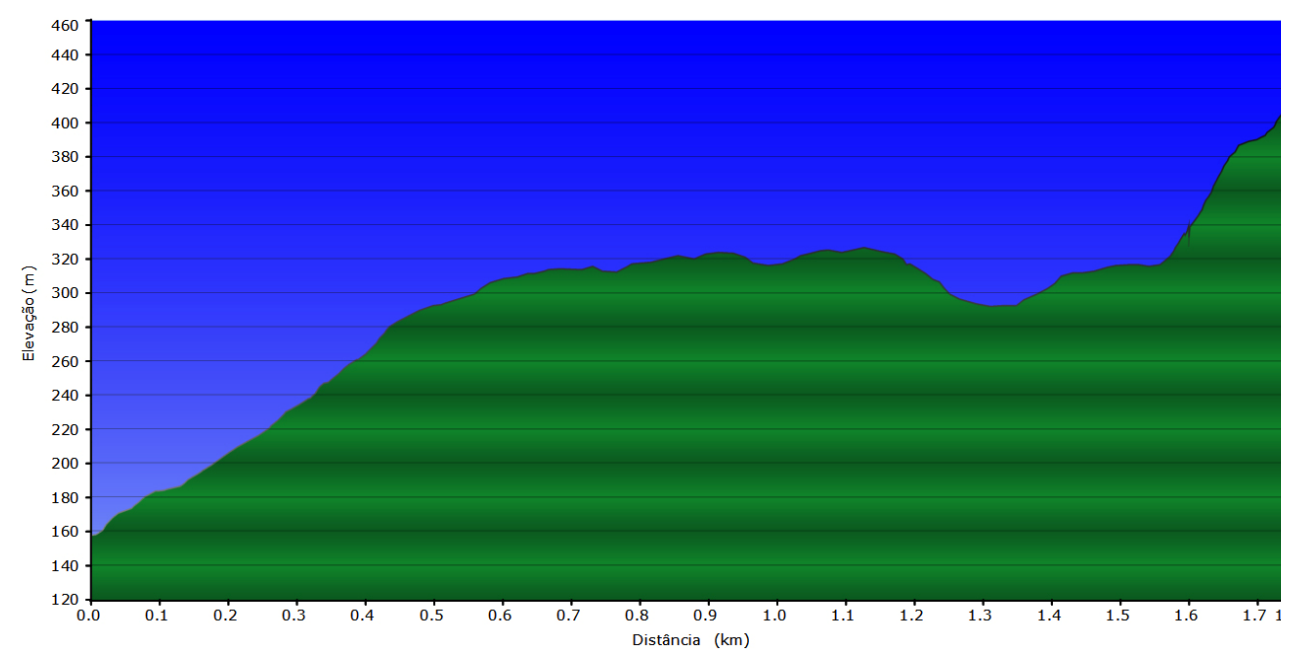

Figura 07 - Perfil topográfico da trilha do Alto Mourão

Como pode ser observado no perfil, existe um trecho mais íngreme na parte rochosa próxima ao ponto culminante (Figura 08). Neste trecho, a trilha passar a ter um nível de dificuldade mais elevado, pois o caminho é percorrido sobre a rocha nua com grande inclinação. Há necessidade de pontos de apoio e, geralmente, os visitantes precisam de ajuda para ultrapassar esse trecho, principalmente aqueles com menor experiência.

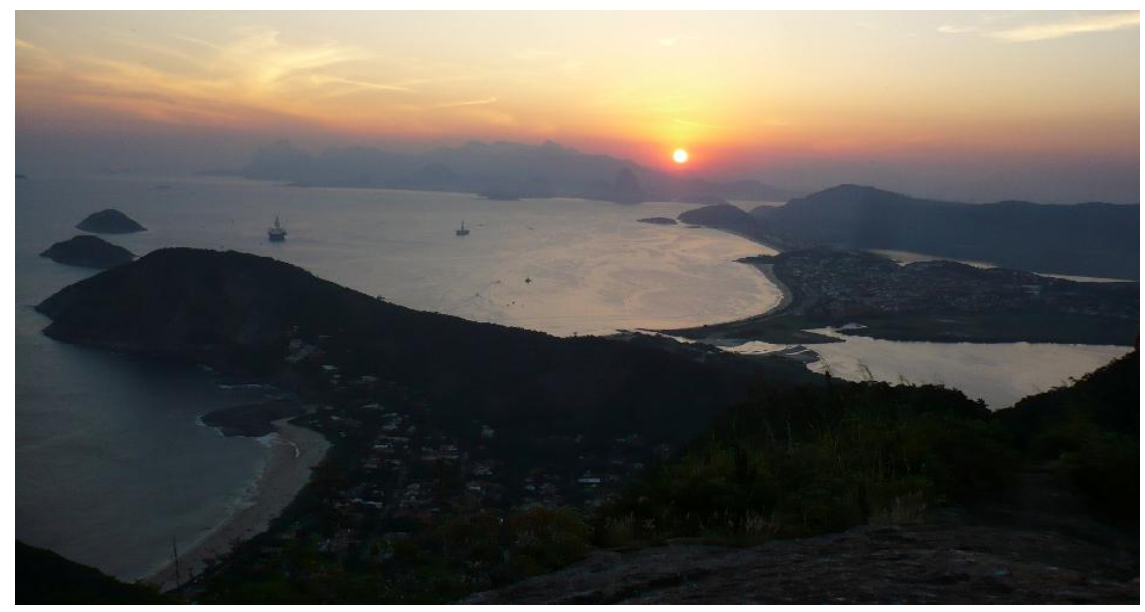

Figura 08. Mirante do Alto Mourão. Praias oceânicas de Niterói (Fonte: Bruno Fernandes) 


\section{c) As Trilhas do Bananal e do Costão de Itacoatiara}

Na figura 09, podem ser observados os trajetos reais gerados pelo GPS das trilhas do Bananal (em amarelo) e Costão (em vermelho). Ambas começam na subsede do parque, bairro de Itacoatiara (Niterói-RJ) e tem o mesmo percurso até o ponto de bifurcação representado pelo marcador em azul na figura, distante 89 metros da entrada da subsede. Neste ponto de bifurcação, os visitantes escolhem a trilha preferencial. A Tabela III apresenta as principais características da Trilha do Bananal.

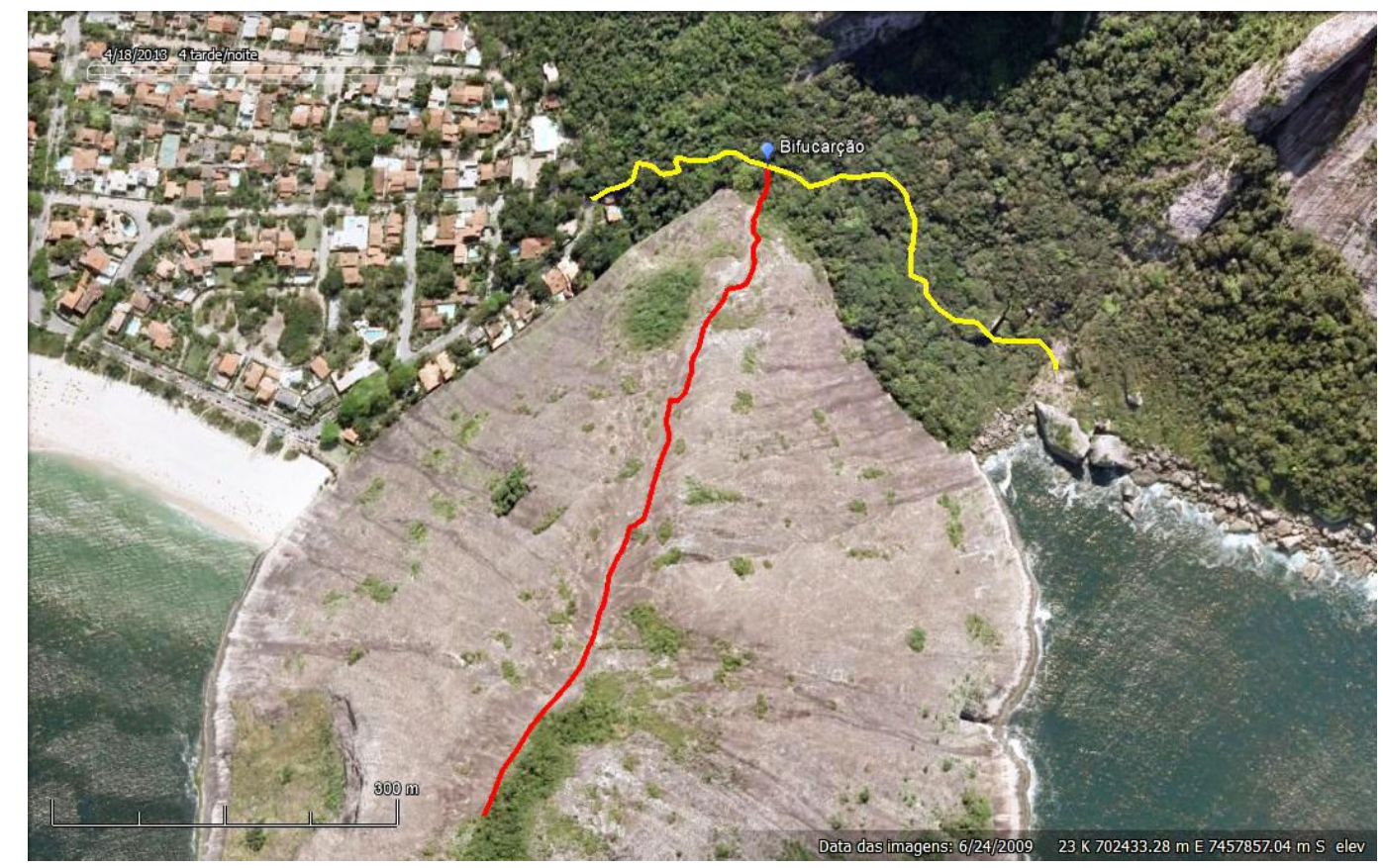

Figura 09. Trajetos das trilhas do Bananal (em amarelo) e Costão (em vermelho) (Fonte Google Earth).

Tabela III. Dados sobre a Trilha do Bananal/PESET

\begin{tabular}{|c|c|}
\hline Característica & Informação \\
\hline Extensão & 504 metros \\
\hline Duração média do percurso & 12 minutos \\
\hline Velocidade média do percurso & $2,52 \mathrm{~km} / \mathrm{h}$ \\
\hline Início da trilha (altitude) & 32 metros (Sede do INEA em Itacoatiara) \\
\hline Final da trilha (altitude) & 23 metros (Enseada do Bananal) \\
\hline
\end{tabular}

Com a marcação de 51 pontos ao longo desse trajeto, foi possível gerar os dados para montagem do perfil topográfico da trilha do Bananal (Figura 10). 


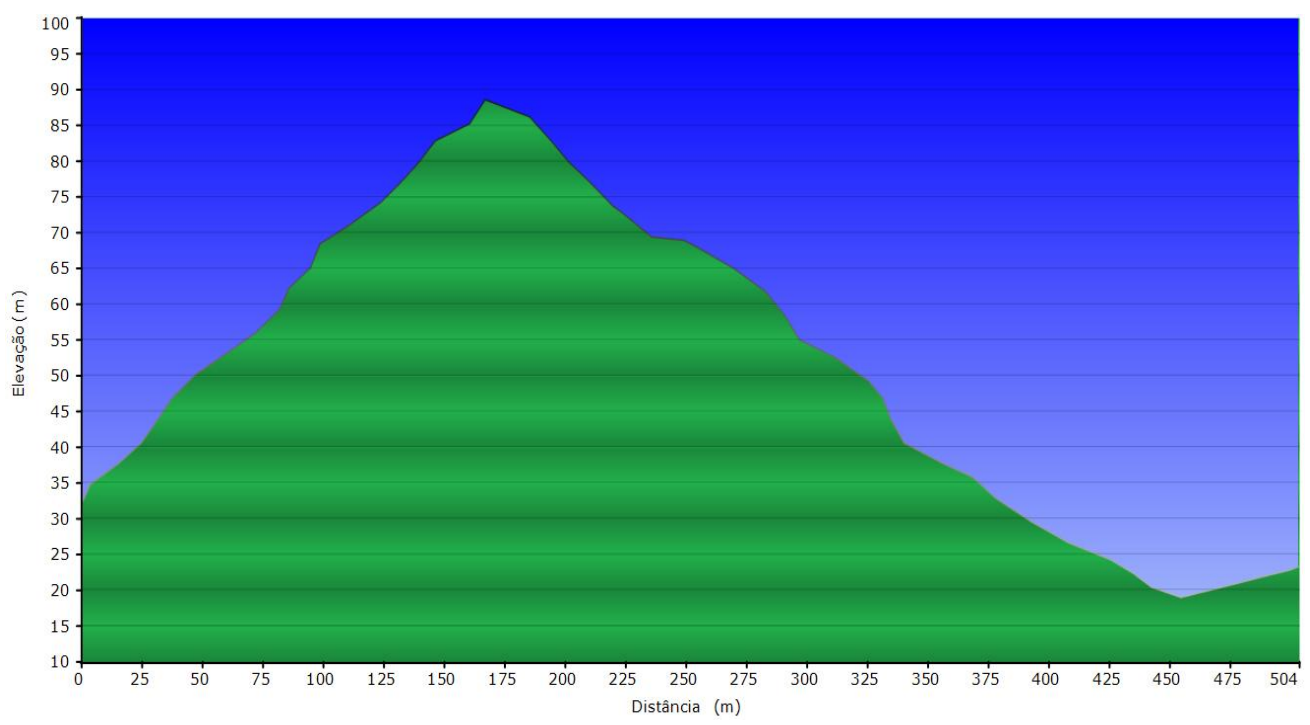

Figura 10. Perfil topográfico da trilha do Bananal, onde o ponto mais alto representa a bifurcação para o Costão ou para a Enseada do Bananal

Com relação à trilha do Costão de Itacoatiara, foram demarcados 108 pontos, gerando os dados da Tabela IV. O perfil topográfico da trilha praticamente coincide com a superfície do afloramento rochoso (Figura 11). Esse afloramento, conhecido também como Pedra do Tucum, serviu de inspiração para criação de um esporte radical conhecido internacionalmente como "Surfe na Montanha", 6 uma atividade que representa uma forma de uso totalmente diferente das tradicionalmente conhecidas para visitação em parques. Considerando que o percurso realizado, a partir da bifurcação, acontece em superfície rochosa, são necessários outros indicadores para avaliação dos impactos do uso público. Isso significa que os indicadores associados ao solo e à erosão, não devem ser utilizados no local. As pichações e os distúrbios causados à vegetação rupestre devem ser considerados neste caso. A Figura 12 ilustra a vista num dos pontos mais altos desta trilha.

Tabela IV. Dados sobre a Trilha do Costão/PESET

\begin{tabular}{|c|c|}
\hline Característica & Informação \\
\hline Extensão & 811 metros \\
\hline Duração média do percurso & 20 minutos \\
\hline Velocidade média do percurso & $2,43 \mathrm{~km} / \mathrm{h}$ \\
\hline Início da trilha (altitude) & 32 metros (Sede do INEA em Itacoatiara) \\
\hline Final da trilha (altitude) & 233 metros (Mirante) \\
\hline
\end{tabular}

\footnotetext{
${ }^{6}$ Clube do Camaleão Alado. Disponível em: 〈http://www.itacoatiara.com/cn_snm.htm. $>$. Acesso em: 21 maio
} 2013. 


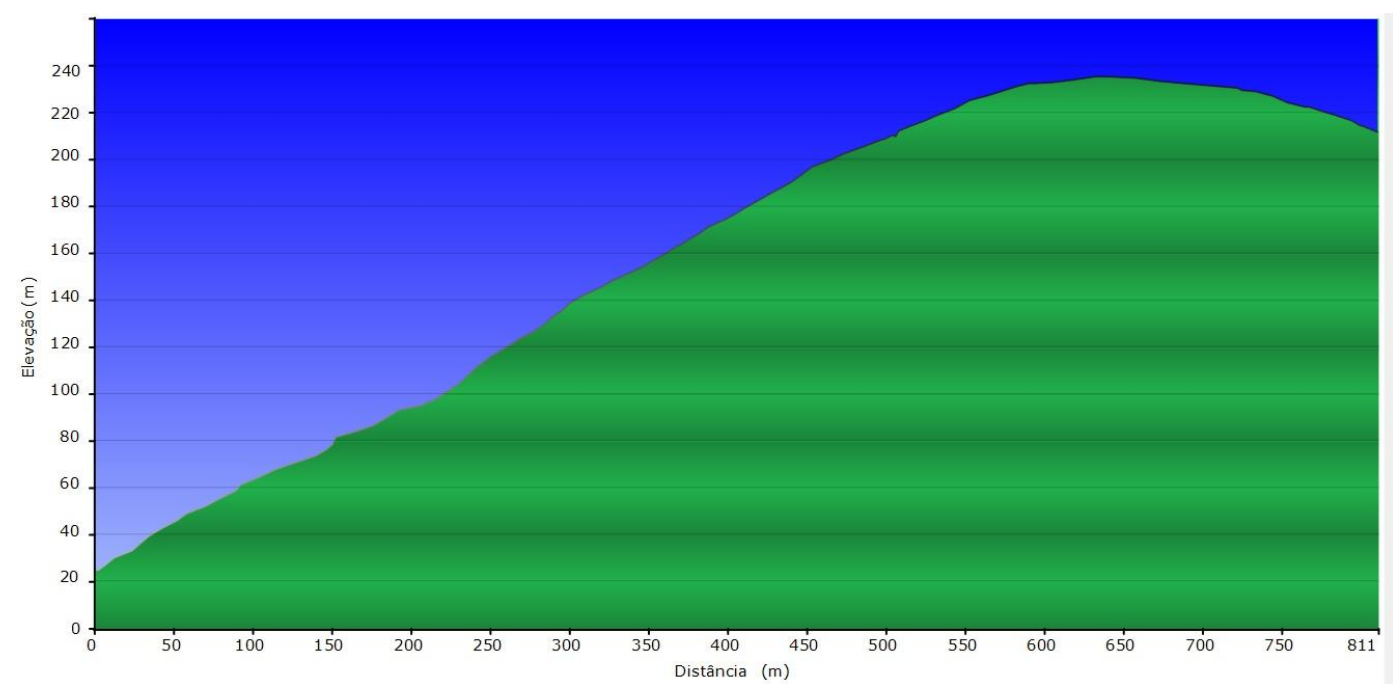

Figura 11. Perfil Topográfico da trilha do Costão

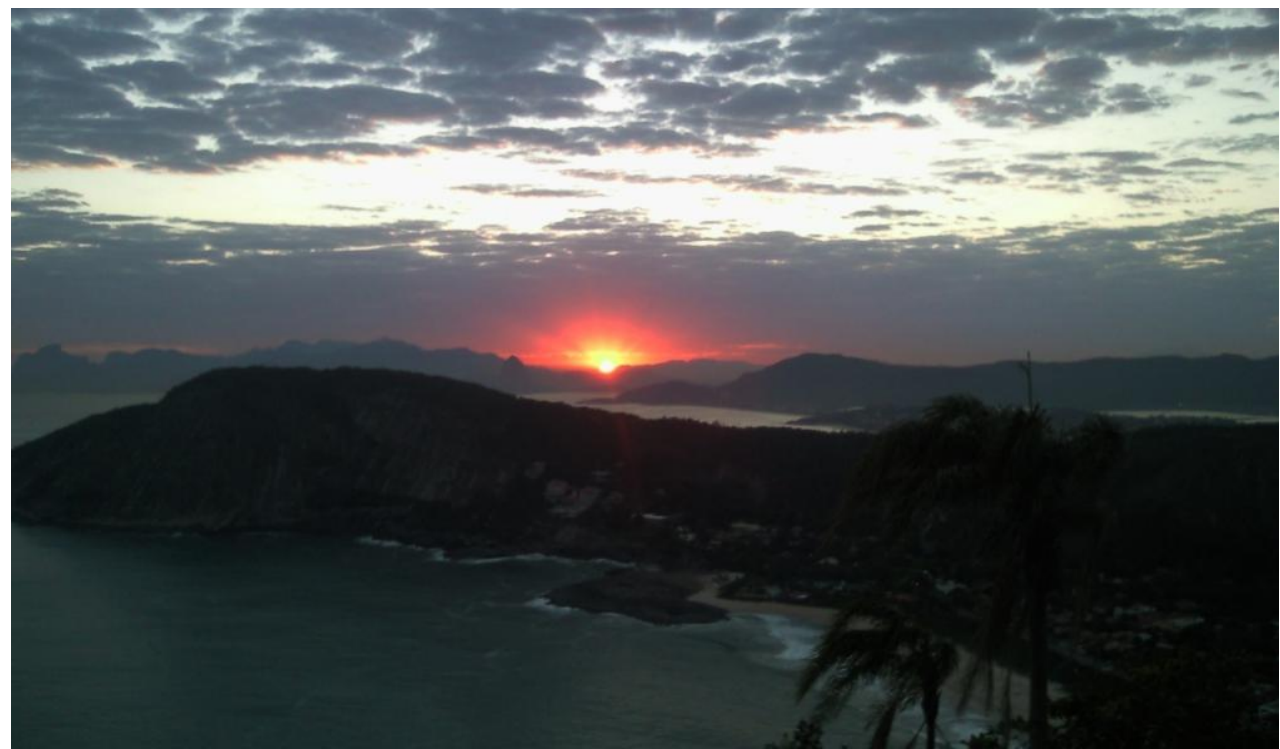

Figura 12. Foto do mirante da Pedra do Costão. Fonte: Bruno Cova

\section{Conclusões}

O uso excessivo das trilhas em parques pode gerar impactos que devem ser monitorados, evitados ou mitigados. As trilhas estudadas apresentam um de nível de dificuldade de médio a alto (trilha do Alto Mourão), no entanto essa avaliação é subjetiva e deve ser adequada ao público alvo e ao tipo de atividade realizada. O PESET localiza-se em área peri-urbana, porém a trilha do Costão de Itacoatiara recebe um grande fluxo de pessoas (Figura 12), para turismo e recreação. Todas as trilhas devem ser planejadas e melhor equipadas com placas informativas e de orientação. 
Os indicadores contribuem para o estabelecimento de uma análise mais precisa sobre as condições da trilha, objetivando sustentar as ações de manejo. Alguns indicadores descrevem a trilhas como bastante impactadas, devido ao seu uso intenso, carência de fiscalização e conservação. Os maiores problemas observados estão no início da trilha do Morro das Andorinhas e do Bananal. Para a trilha do Costão de Itacoatiara, pretende-se sugerir indicadores específicos para trechos de rocha nua. Os mais factíveis estão relacionados ao comportamento do visitante, como a presença de pichações e lixo, bem como a área ocupada pela vegetação. Atualmente, a primeira vem sendo utilizada para trabalhos de Educação Ambiental. Assim, é importante o seu planejamento e estabelecimento de pontos de interpretação ambiental. Como as atividades envolvem crianças, as questões de segurança são primordiais e a trilha deve ser bem planejada e estruturada. O PESET entrou no programa de estruturação de trilhas para o esperado aumento de visitação na Copa do Mundo e Olimpíadas. É preciso que a administração do Parque esteja atenta às possíveis transformações relacionadas ao uso público e trabalhos acadêmicos podem contribuir para o seu monitoramento.

\section{Referências bibliográficas}

BAYFIELD, N.G. Approaches to reinstatement of damage footpaths in the Three Peaks area of the Yorkshire Dales National Park.In Beel, M. Bunce, R.G. H. (Ed.) Agriculture and conservation in the hills and uplands.Grand-over-sands.NERC/ITE, 1987. p. 78-87.

\section{BAYFIELD, N.G.; McGOWANN, G.M. Footpath Survey-1986.Institute of Terrestrial}

Ecology.Three Peaks Project. ITE Report No. 1, Banchory, Escócia, 1986. 49 p.

BRASIL. Lei $N^{\circ}$ 9.985, de 18 de julho de 2000. Decreto no 4.940, de 22 de Agosto de 2002. Institui o Sistema Nacional de Unidades de Conservação da Natureza (SNUC). Brasília: IBAMA, Diretoria de Ecossistemas, 2002. 35 p.

FIGUEREIDO, M. A; BRITO, I. A; SANTANA, W.A et al. Compactação do Solo em Trilhas de Unidades de Conservação. Mercator, v. 9, n. 19, p. 165-174, 2010.

MAGRO, T. C. Impactos do Uso Público em uma trilha no Planalto do Parque Nacional de Itatiaia. 1999. 135 f. Tese (Doutorado em Engenharia Florestal) - Escola de Engenharia de São Carlos. Universidade de São Paulo. São Carlos.

MAGRO, T.C.; FREIXÊDAS, V.M. Trilhas: Como Facilitar a Seleção de Pontos Interpretativos. Circular Técnica IPEF, 1998.

PASSOLD, A.J.; MAGRO, T.C.; COUTO, T.Z. Comparing indicator effectiveness for monitoring visitor impact at Intervales State Park, Brazil: Park Ranger- Measured Versus Specialist-Measured Experience. Working Papers of the Finnish Forest Research Institute, v. 2, p. 51-57, 2004.

PIMENTEL, D.S. Os parques de papel e o papel social dos parques, 2008. 254 f. Tese (Doutorado em Recursos Florestais) Escola Superior de Agricultura Luiz de Queiroz Universidade de São Paulo. 2008.

PIMENTEL, D.S; MAGRO, T.C. Múltiplos olhares, muitas imagens: O manejo de parques com base na complexidade social 2011. GEOgraphia - Revista do Programa de Pós-Graduação em Geografia da Universidade Federal Fluminense, p.92-113, 2012. 